\title{
VOCES CREATIVAS
}





\title{
Barrancas de San Nicolás
}

\section{Por Gabriel Ferrer Ruiz ${ }^{1}$}

\author{
Para Guillermo Tedio
}

Isla encendida en el agua

polvo reciente

ligera estrella en las barrancas del Magdalena

La brisa esculpe montañas de tierra

Canta el sol en el Caribe:

paisaje de alegre púrpura

En el aire húmedo del río

los párpados crecen para ver a Dios

Un silencio cae en la llanura sedienta de robles

Ánimo repartido desde el puerto

donde los sueños se levantan temprano

para capturar el milagro

que no alcanza a revelarse.

\footnotetext{
${ }^{1}$ Magíster en Literatura Latinoamericana del Instituto Caro y Cuervo de Bogotá y Doctor en Letras de la Universidad Nacional Autónoma de México. Docente investigador de la Universidad del Atlántico. Ha publicado dos libros de poemas: Veredas y otros poemas y Sinuario, y un libro de ensayos titulado Etnoliteratura Wayuu: estudios críticos y selección de textos (1998). Es director del Centro de Estudio e Investigaciones Literarias del Caribe (Ceilika) y de la revista Cuadernos de Literatura del Caribe e Hispanoamérica. El presente poema hace parte del libro inédito Festejos (1997-2008). Correo electrónico: sinuario@yahoo.com.
} 
II

Habla la memoria

en medio de vientos huracanados

Aleteos de claror

atraviesan el Caño de las Compañías

mientras un varadero de canoas

mitiga el fogaje de la soledad

Desde allí el sol oficia su liturgia:

Recién llegados

a la Plaza de San Nicolás

sueñan con el resplandor de la luz

con los cantos de arena

Allí

en la pupila de los caminantes

el río se convierte en remolino

Imposible salir del agua

cuando se nace de su dolor

Nada entonces

como volver al principio

cuando ella desembocaba en nuestros sueños. 


\section{III}

Asumo desde ahora el primer viento -dice Juan Bernardo Elbers

Nunca desatenderé

el llamado de luz que me hizo dibujar esta ciudad de orillas y navíos

¿Acaso no supo también Pierre D’Espagnat

del lago interior

que dormía en la ensenada de Salgar?

Lamentó los extensos pastizales

que azotaban el Canal de la Piña

Entre recuerdos

habló con amargura

de las pasiones desatadas

a treinta grados

en las casas de barro y de bambú

Entre mangles viejos y duros

el aire espió

desde el fuerte del Castillo

Barcos derretidos en el bochorno

entraron al Magdalena

llenos de mercaderías. 


\section{IV}

La respiración de la sal aligera cualquier pena

Faldas cortas levanta la brisa

Un deleite de ojos asalta las caderas en la antigua calle de Las Vacas

La ciudad

arbusto a la orilla del río

aspira el perfume del yodo

Edificios decrépitos en el Paseo Bolívar

se inclinan hacia el mercado

aturdido por gruñidos de cerdos

Nubes de mosquitos

se amotinan sobre el olor de las frutas

Desdentados ancianos sudan

en el territorio de los tamarindos

con el sabor agrio de la tarde

Por galerías se expande un murmullo

de voces que regatean la ternura

Se derrama el achiote en un barro enrojecido

como si la sangre reconstruyera al primer Adán

Un asalto

y el ladrón vuela en la pereza de la brisa

que danza en el miedo de las muchedumbres

La Plaza de San Nicolás

es una herida antigua

que supura entre el mendigo y la campana. 
Un soñador

desde la Torre

más alta de la ciudad

mira con ojos orientales

las dormidas aguas del Magdalena

Ladys Ena

viaja en una barca de caoba

Una atarraya se abre

para recoger su efímera alegría

En la Vía Cuarenta

un festejo se levanta

Sudor y pasión crecen en la Danza del Garabato

Movimientos de caderas se despliegan

temblores que anticipan a la muerte

El tambor y la gaita aniquilan la tristeza

La primavera

con su perfume

incita al gozo de la tarde

Nadie apaga la vela

arrebato de la memoria

de los antepasados

que aún bailan en las tumbas

torito y culebra

golero, caimán y sapo

saludan a la jungla ardiente

No es otro el placer que el movimiento

Las negras regalan sus caderas al ritmo

Los negros sacuden su música mandinga

como si fuera un árbol contra la tristeza. 
La ciudad es toda puertas

arena amarilla lastimada

agua en marcha y agua detenida

Cíclicas mareas golpean los labios rocosos de Bocas de Ceniza

Vientos Alisios

engendran la corrosión del salitre

en la conciencia y en los clavos

Un escándalo jadeante pesca en el bostezo del Magdalena

Amigos tejen ideas en Sabanilla

Hay un aliento emergido

En las riberas amargas de Galerazamba

Batallas de sal ofenden la retina

Una sílaba desconocida

se columpia en Puerto Mocho

De la oración surgen sacerdotes

que destierran viejos malestares:

El agua bautiza al pecado

Hombres y mujeres

producen un motín de amor

al final del día en Puerto Colombia. 


\section{VII}

Crece una luna desbocada

en medio del diluvio de los nísperos

Se prolonga el monólogo de la lluvia

en estos días de festejos y cortejos fúnebres

que besan mano a la misma hora

El corazón es habitado por un festín de palabras

que sucumben como pájaros desplumados

Un rumor

una ráfaga sacude los confines de la ciudad

Enredaderas de miedo

escalan por los huesos hasta el alma

Pájaros sin alas

saltan aturdidos en el fango

al final de un sendero blanco

Visiones de niños revelan ciertos ritmos

en la Batalla de Flores

bálsamo ufano

en medio de rastrojos que mendigan mendrugos

Viajeros extraños y desterrados palpitan en el caimito

Se siente una nostalgia de buenos días

de edénicas palmadas

para no morir de soledad

A pesar de todo

aquí no pasa nada

La gente muere con los años

y aún hay soles en los ojos. 


\section{VIII}

Un perro ladra al hombre miserable

que entra a la casa sin permiso

La gente habla del infierno

de donde el diablo ha huido

Uñas de obsidiana sangran la oscuridad

mientras en la luz

el plumaje de papagayos

incinera la isla

Un hombre caimán navega sobre la piel del río

Se palpa una presencia de gargantas silenciadas que endulzan como semillas la tierra

No alcanzamos a escuchar los latidos del corazón herido

Alguien dora el amor con manos amargas sobre brasas de mangle

$\mathrm{Al}$ otro lado del río los muertos zumban

Se cierran los ataúdes mientras gravita el odio

El embarcadero se aleja en la mirada

De nuevo se levanta el sol mientras el río se engolosina con la esencia pestilente de los cuerpos que duermen para siempre

El cauce arroja breves luces como estrellas fugitivas

En la ribera el dolor fustiga la memoria rastrea un mango de maciza inocencia

Alguien desea atravesar el agua para alcanzar el delirio de la noche en la rama más alta de la ceiba milenaria

Un relámpago ocioso lastima al crepúsculo anunciando la inundación que avanza. 
IX

Una pena viva

abre los ojos

cuando al otro lado de la ciudad

la sombra se enfrenta a la luz

La tibia noche aroma al trupillo

fundiendo su vida silente con las hojas

A la luz vertiginosa

la locuaz llama de una vela

brota el amor

y el sueño funda una edad interminable

Nacen ganas

de tocar un pecho adolescente de ceiba roja

mientras arden la frente y el brasero

También la palabra es valedera

Los días esperan el camino de la parlería

Las nubes profanan el dolor

así nomás

con suavidad

La amistad se consagra

cuando los brazos se abren. 


\section{$\mathbf{X}$}

Queremos otra temporada más

para recobrar los hilos invisibles

de esta isla que pone a prueba la memoria

Descubriremos quiénes somos

al descender por la música y el aroma

que se enredan en el follaje del tabaco

Hay una extraña comunión de humedades

en esta ciudad de arcilla y agua nueva

El son y la puya vallenata ofrendas a la alegría

adoran la danza en la Puerta de Oro

Como un reloj de arena

canta el torrente

El mar escribe prodigios

La luz gira en la madera

ventana por donde Dios se asoma

para ahondar en la brisa del último invierno

En el campo abierto del Simón Bolívar

cortinas de aire levantan un avión

piloto Hellmuth Von Khron

Saludos del primer vuelo

Arenas altas del Cortissoz

se dilatan en mil novecientos diecinueve

El milagro de Scadta se hace tragedia

después de la oración en el rito de los vientos

Es fácil hollar espacios transparentes

encontrar los nombres:

Aduana

Estación Montoya

Banco Comercial de Barranquilla

Allí las raíces del ajenjo y los matarratones

Allí el mamón santificando la sombra con su agria dulzura

Un raro designio nos emparenta con los fenicios 
Los Márquez

los Parrish

los Blanco

los Nieto Arteta

trazan huellas en la luz que nos escolta

Palabras

gestos

inventos

rituales

mitos

vacilaciones

y extraños navíos

se juntan en la marea febril

oficiando el letargo y la sagrada lentitud que nos atollan

Un plumaje nuevo nos invade:

escritura de la memoria

letra salobre

espuma del presente

Reinos y playas nos eclipsan

Veleros borrachos atizan ausencias de linajes y castas

Levedad y afirmación alcanzan aquí su desenlace

Una sencilla épica adolescente

nos dibuja magníficos en la claridad del trópico

Nuestras cicatrices han sanado con el mar y el río

porque nacimos del dolor del agua. 
